\title{
Identification of Different Pink Pomelo Varieties by Gas Chromatography-mass Spectrometry and Olfactometry Coupled to Chemometrics
}

\author{
Ge Gao $^{1,2}$, Noopur Gosavi ${ }^{3}$, Xueli Pang ${ }^{4}$, Hui Zou ${ }^{1}$, Haihua Liu ${ }^{1}$, Yan Ma ${ }^{1,5}, Z_{\text {Zhenzhen Xu }}^{2, *}$, Xiaojun Liao ${ }^{1}$ \\ ${ }^{1}$ College of Food Science and Nutritional Engineering, China Agricultural University; Beijing Advanced Innovation Center for Food \\ Nutrition and Human Health; National Engineering Research Centre for Fruit and Vegetable Processing; Key Lab of Fruit and \\ Vegetable Processing, Ministry of Agriculture, Beijing Key Laboratory for Food Nonthermal Processing, Beijing 100083, China \\ ${ }^{2}$ Institute of Quality Standard \& Testing Technology for Agro-Products, Chinese Academy of Agricultural Sciences; Key Laboratory \\ of Agro-food Safety and Quality, Ministry of Agriculture, Beijing 100081, China \\ ${ }^{3}$ Department of Food Science, Rutgers, The State University of New Jersey, 65 Dudley Road, New Brunswick, NJ 08901, USA \\ ${ }^{4}$ Laboratory of Quality \& Safety Risk Assessment for Tobacco, Ministry of Agriculture, Tobacco Research Institute of Chinese \\ Academy of Agricultural Sciences, Qingdao, China 266101 \\ ${ }^{5}$ Institute of Agro-products Storage and Processing, Xinjiang Academy of Agricultural Sciences, Urumqi, 830091, China \\ *Corresponding author: xuzhenzhen@caas.cn
}

\begin{abstract}
To differentiate different kinds of pink pomelos, which came from the main producing area of pink pomelo varieties in China, headspace solid-phase microextraction (HS-SPME) coupled with gas chromatographymass spectrometry and olfactometry (GC-MS-O) was used to determinate and characterize volatile profiles of different varieties. Olefins, alcohols, ketones represented the most abundant volatile compounds in all varieties of pink pomelo juices. There are 38 aroma-active compounds perceived by the trained panel of judges by using detection frequency analysis method (DFA). Principal components analysis (PCA) combining GC-MS analysis was applied and successfully distinguished six varieties of pink pomelo juices from four different geographical regions of China, which is in accordance with their vegetal sampling location. Further, partial least squares-discriminant analysis (PLS-DA) indicated that this model is good in correlating citrus odor. Decanal, hexan-1-ol, $\gamma$-selinene could be identified as the main characteristics to distinguish different varieties.
\end{abstract}

Keywords: pink pomelo, geographical identification, GC-MS, PCA, PLS-DA

Cite This Article: Ge Gao, Noopur Gosavi, Xueli Pang, Hui Zou, Haihua Liu, Yan Ma, Zhenzhen Xu, and Xiaojun Liao, "Identification of Different Pink Pomelo Varieties by Gas Chromatography-mass Spectrometry and Olfactometry Coupled to Chemometrics." Journal of Food and Nutrition Research, vol. 6, no. 3 (2018): 158-167. doi: $10.12691 / \mathrm{jfnr}-6-3-4$.

\section{Introduction}

Pomelo (Citrus grandis (L.) Osbeck) belongs to the family Rutaceae. The pomelo is native to China, southeastern Asia and America (FAO). As the largest citrus fruit, the pomelo weights as much as $10 \mathrm{~kg}$ and grows as large as $30 \mathrm{~cm}$ in diameter. Its flesh is rich in juice and flavor, which tastes sweet, or slightly acidic with a bit of bitterness, probably attributed to the biological glycosides contained in it [1]. It is classified as common (or yellow and white) or pigmented (or pink). Compared to white pomelo juice, pink pomelo juice not only attracted more customers, but also contained higher amount of volatile profiles, such as alcohols and aldehydes [2].

At present, authenticity identification is an important issue for food quality and safety control and has been applied by many researchers in several foods [3]. To explore these studies, many analytical methods, especially based on chromatography and mass spectrometry techniques, were proved to be useful. High performance liquid chromatography (HPLC) $[2,4]$, thin-layer chromatography (TLC) [4], electrospray ionization mass spectrometry (ESI-MS) [5], liquid chromatography triple quadrupole tandem mass spectrometry (LC-QQQ-MS/MS) [6], were all frequently used to achieve the goal. Spectroscopic techniques, including FT-IR, 2D, IR, UV, even Terahertz spectroscopy [7] and Near-Infrared spectroscopy, and NMR spectroscopy were also carried out [8]. In China, pomelos have a lot of varieties and mainly grown in several southern provinces with the warm and moist climate, such as Fujian, Jiangxi, Zhejiang and Chongqing. Usually, customers prefer to purchase pomelos with a few specific various, however, it is hardly for them to identify the different pomelos, especially for those with similar appearances. Therefore, the authenticity analysis of pink pomelo varieties is deeply needed.

As a successful technique, gas chromatography mass spectrometer GC-MS is widely applied in the field of sensory evaluation, with the advantage of lower sample 
size, lower detection limits and high sensitivity [9]. Recently, headspace solid-phase microextraction (HS-SPME) GC-MS and multivariate statistics were developed to evaluate volatile constitutes like honey [3], flower [10], pears [11], almonds [12], peaches [13], beer [14], tea oil [9], peanuts [15], pesticide [16]. Combining the GC-MS technique, a lot of recent research has been applied for the authentication of geographical origin of food, beverage, wine et al. In addition, based on the large amount of GC-MS, several statistic methods were coupled with this technique for the certification of botanical origins [17]. There are many studies focused on the volatiles of pomelo blossom and peel, but limited one is systematically proposed on the volatiles of pomelo juice, especially the pink pomelo. In this paper, we conducted the study of volatile components and identification of six pink pomelo varieties from China. We explored this work by SPME with GC-MS-O coupling with chemometric method.

\section{Materials and Methods}

\subsection{Pink Pomelo Juice Samples}

Pink pomelo fruit from China were picked and purchased during their harvesting period between November 2015 and January 2016. Six varieties of pink pomelo were selected from four different geographical regions of China: FD (Fengdu), MJ (Shangrao), NH (Ganzhou), RY (Ganzhou), PH (Guanxi), SH (Guanxi). More information about the cultivars is provided in Table 1 and Table 2. All fresh pink pomelo fruits were immediately refrigerated, transported to the laboratory, and juiced with a screw extractor (GT6G7, Zhejiang Jixie Co., Zhejiang, China).
The pink pomelo juices were filled into $60-\mathrm{mL}$ EVOH plastic bottles and frozen in liquid nitrogen within $12 \mathrm{~h}$ and stored at $-80{ }^{\circ} \mathrm{C}$ to minimize the loss of any volatile constituents.

\subsection{Physicochemical Properties}

The pink pomelo juices were equilibrated at $25 \pm 2{ }^{\circ} \mathrm{C}$ to measure physicochemical properties, i.e. $\mathrm{pH}$ value, TA and TSS. The $\mathrm{pH}$ was tested by Thermo Orion $868 \mathrm{pH}$ meter (Thermo Fisher Scientific, Inc., MA, U.S.A). TA was quantified by 842 GPD titrino, automatic potentiometric titrator (Metrohm, Switzerland) and the data was expressed as percentages of citric acid content. TSS was evaluated by WAY-2S digital Abbe refractionmeter (Shanghai Precision and Scientific Instrument Co., Shanghai, China), and the results were showed as ${ }^{\circ}$ Brix.

Total phenols were quantified by the Folin-Ciocalteau method by a spectrophotometer (UV-726, Shanghai Precision and Scientific Instrument Co., Shanghai, China) described by Singleton et al [18] with some modifications, and the results were expressed as $\mathrm{mg}$ of gallic acid equivalent (GAE) per $100 \mathrm{~g}$ pink pomelo juice. The color value was determined by the color measurement spectrophotometer (Hunter Lab Color Quest XE, Hunter Associates Laboratory, Inc., Virginia, USA) in the reflectance mode. To analyze sugar, the liquid chromatograph (LC-20AT) combined with UV/Vis detector (SPD-20AV), as well as the auto sampler (SIL-20A) with column oven (CTO-20A) from Shimadzu Co., Japan, equipped with the Sunfire TM C18, (Waters, $4.6 \times 250 \mathrm{~mm}$ i.d, $5 \mu \mathrm{m}$ particle size), was used as described, the content of respective sugars in pink pomelo juices were quantified by the standard curve with R2 greater than 0.99 was plotted [19].

Table 1. Origins and colors of different pink pomelo juices from China

\begin{tabular}{|c|c|c|c|c|c|c|}
\hline \multirow[t]{2}{*}{ Samples } & \multirow{2}{*}{ Origins } & \multirow{2}{*}{ Locality } & \multirow[t]{2}{*}{ Color } & \multicolumn{3}{|c|}{ Color index } \\
\hline & & & & $L^{*}$ & $a^{*}$ & $b^{*}$ \\
\hline FD & Chongqing & Fengdu & Pink & $34.45 \pm 0.36^{\mathrm{c}}$ & $0.52 \pm 0.35^{\mathrm{d}}$ & $1.22 \pm 0.23^{\mathrm{e}}$ \\
\hline MJ & Jiangxi & Shangrao & Pink & $35.39 \pm 0.79^{d}$ & $-0.86 \pm 0.25^{\mathrm{b}}$ & $0.63 \pm 0.15^{\mathrm{d}}$ \\
\hline $\mathrm{NH}$ & Jiangxi & Ganzhou & Slight Red & $33.27 \pm 0.25^{\mathrm{a}}$ & $-1.29 \pm 0.18^{\mathrm{a}}$ & $-0.79 \pm 0.23^{\mathrm{a}}$ \\
\hline RY & Jiangxi & Ganzhou & Slight Red & $33.88 \pm 0.26^{\mathrm{b}}$ & $-0.44 \pm 0.18^{\mathrm{c}}$ & $-0.33 \pm 0.16^{\mathrm{b}}$ \\
\hline PH & Fujian & Guanxi & Slight Yellow & $34.69 \pm 0.25^{\mathrm{c}}$ & $-0.72 \pm 0.15^{\mathrm{b}}$ & $-0.78 \pm 0.18^{a}$ \\
\hline $\mathrm{SH}$ & Fujian & Guanxi & Red & $33.83 \pm 0.31^{\mathrm{b}}$ & $0.9 \pm 0.22^{\mathrm{e}}$ & $0.16 \pm 0.34^{\mathrm{c}}$ \\
\hline
\end{tabular}

All data were the means $\pm \mathrm{SD}, \mathrm{n}=3$. Values with different letters within one row are significantly different $(P<0.05)$.

Table 2. The physicochemical properties of different pink pomelo juices from China

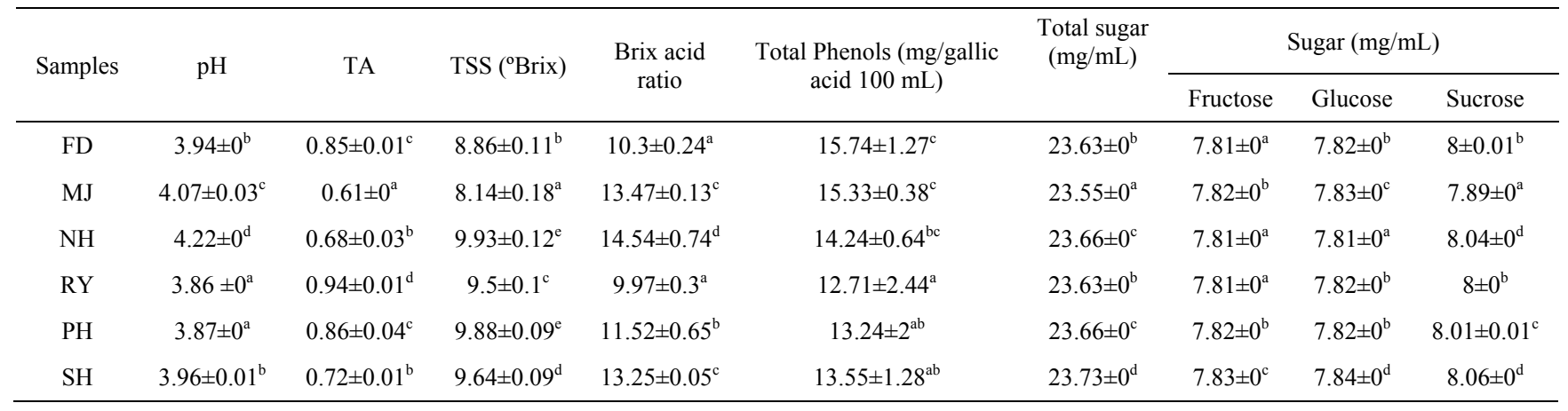

TA, total acid. TSS, total soluble solids. All data were the means $\pm \mathrm{SD}, \mathrm{n}=3$. Values with different letters within one row are significantly different $(P<0.05)$. 


\subsection{Headspace Solid-phase Microextraction}

The pink pomelo juices were put in a sealed glass flask and equilibrated for $10 \mathrm{~min}$ at $40^{\circ} \mathrm{C}$ in water bath. A manual headspace solid-phase micro-extraction (HS-SPME, Supelco, Inc., Bellefonte, PA, USA) device was used to extract volatile components of pink pomelo juices. A volume of $20 \mathrm{~mL}$ infusion was transferred to a screw cap headspace vial (50 mL; Beijing Bomex Co., Beijing, China) and equilibrated in the same condition in which $20 \mu \mathrm{L}$ blended internal standard was added. We exposed the fiber coated with 50/30-lm polydimethylsiloxane/divinylbenzene/carboxen to the headspace of the vial in $40^{\circ} \mathrm{C}$ for $30 \mathrm{~min}$ with agitation at 90 RPM [20]. Internal standards of cyclohexanone were purchased from Sigma-Aldrich Co., Ltd. (Milwaukee, WI, USA) with purity $>99 \%$. N-Alkanes (C5-C40), which was used to make linear retention index (LRI) calculation, was obtained from J\&K Chemical Ltd. (Beijing, China).

\subsection{Gas Chromatography-mass Spectrometry Analysis}

The SPME extract was injected into the port of an Agilent 7890A-5975C GC/MSD (Agilent Technologies) equipped with a DB-5 capillary column $(30 \mathrm{~m} \times 0.25 \mathrm{~mm}$, $0.25 \mu \mathrm{m}$ film thickness), and desorbed at $250{ }^{\circ} \mathrm{C}$ for $3 \mathrm{~min}$. The helium (99.999\% purity) was used as the carrier gas for vial pressurization and circulated in split mode (1:50). The flow rate was maintained at $1 \mathrm{~mL} / \mathrm{min}$. The oven temperature was initially kept at $40{ }^{\circ} \mathrm{C}$ for $3 \mathrm{~min}$, which was then increased at $2{ }^{\circ} \mathrm{C} \mathrm{min}-1$ to $140{ }^{\circ} \mathrm{C}$, and again at $20{ }^{\circ} \mathrm{C}$ min- 1 to $250{ }^{\circ} \mathrm{C}$ where it was held for 6 mins. The mass detection was conducted with electronic impact (EI) mode at $70 \mathrm{eV}$, and source temperature was operated at $250{ }^{\circ} \mathrm{C}$. The mass spectrum was scanned in the range of $\mathrm{m} / \mathrm{z} 39$ to $450 \mathrm{amu}$ at $1 \mathrm{~s}$ intervals. The volatiles were indentified by matching the mass spectra with their data in the National Institute of Standards and Technology (NIST08), and confirmed with the retention index (RI, error $<5 \%$ ), as well as aroma description (AD). The volatile components chosen in this paper, has gave the similarity of more than 70 (maximum data is 100).

\subsection{Gas Chromatography-olfactometry}

The sniffing port (Sniffer 9000, Brechbühler, Switzerland) combined with a GC-MS (7890A- 5975C, Agilent Technologies, Inc.) was used to detect the odor-active components. Equipped with a capillary column, the effluents were split 1:1 (by volume) into a sniffing port and a MS detector using the Agilent capillary flow technology. The transfer line to the GC-O sniffing port was set at $240^{\circ} \mathrm{C}$. The GC-MS conditions and sample preparation were same as those described above.

Eight trained assessors, who were a mixed group of both sexes, in the age group of 20 to 50 years participated in the detection frequency analysis to sniff the GC effluent and give their data by GC-O analysis. The panelists were professional trained prior to the sensory evaluation in order to be familiar with odor descriptions of characteristics and intensities for artificial odorants and different pink pomelo juices. Eight GC-O runs were conducted (one run for each assessor) to perceive aroma-active compounds from the sniffing mask. Any odorant was considered to have potential aroma activity whose detection frequencies was more than twice [21].

\subsection{Statistical Data Analysis}

The data was analyzed by performing ANOVA (analysis of variance) using SPSS, version 17.0 (SPSS Inc., 2009) and Duncan's test. Significant differences were established at $\mathrm{P}<0.05$. Results have been presented as mean \pm standard deviation. All experiments were performed in triplicates. Multivariate analysis was conducted using PCA based on the correlation matrix to determine which volatiles contributed most to differentiate the pink pomelo juices from different origins.

\section{Results and Discussion}

\subsection{Physicochemical Properties of Pink Pomelo Juices}

The physicochemical properties play an important role in determining the quality and attracting customers of citrus and pomelos juices. As a liquid-solid suspension system, when determined several citrus volatiles, the sample volume and aroma threshold also could be affected by the physicochemical properties such as sugars and pulp $[2,22]$. As shown in Table 2, there is a significant difference of $\mathrm{pH}, \mathrm{TA}, \mathrm{TSS}$ and Brix acid ratio among these six cultivars $(\mathrm{P}<0.05)$. As studied in our previous research [23], these phychemical properties has given the similar data. The significant difference of the color indexes and total phenols were also observed in all six cultivars. Visually, a pink appears in cultivars FD, MJ and $\mathrm{PH}$, and a slight red appears in cultivars $\mathrm{NH}, \mathrm{RY}$ and $\mathrm{SH}$. The content of total sugar, fructose, glucose and sucrose showed a similar level among these cultivars. Also the similar content of total sugars were observed in other grapefruit and sweet lemons [24].

\subsection{Characterization of Volatile Compounds Analyzed by HS-SPME-GC-MS}

Figure 1 shows the volatile compounds and their relative content extracted from pink pomelo juices by HSSPME. The volatiles of pink pomelo juice samples were identified and categorized as alkanes, olefins, aldehydes, alcohol, phenols, ketones, esters, benzenes and others. Obviously, olefins are the most abundant compounds in pink pomelo juices, followed by alcohols, ketones, aldehydes, and other kinds of components, which was also reported by other studies [25]. Contrast with the pomelo juices from Malaysian, all cultivars of pomelo juices had more volatile components in our study [2]. The average values (mean \pm standard deviation) of the concentrations of these volatile profiles, which were evaluated in triplicate of the six pink pomelo juices, are listed in Table 3. According to the data, some volatile components such as D-limonene (A6), nonanal (B3), decanal (B4), hexan-1-ol (C2) presented in all pink pomelo juices. D-limonene and nonanal were reported as the important volatiles in most pomelo and citrus fruits [2]. There are also some volatile 
compounds which are specific to certain varieties, such as $\beta$-pinene (A3), elemene (A17), nootkatone (D2) were only detected in FD samples; and para-menthatriene (A5), germacrene B (A23), guaiene (A36) were only detected in MJ samples. Isocaryophyllene (A20) and para-cymene (E1) were only presented in $\mathrm{PH}$ samples; while (E)-oct-2-enal (B2) were only existed in SH samples. Probably because of different geographical regions, there is a significant difference among different pink pomelo juices, not only in the composition of volatiles but also in the relative content [26].

Table 3. The composition and relative content (\%) of volatiles identified by SPME/GC-MS in different pink pomelo juices from China






\begin{tabular}{|c|c|c|c|c|c|c|c|c|c|c|}
\hline \multirow{2}{*}{ Peak } & \multirow{2}{*}{ Code $^{a}$} & \multirow{2}{*}{$\mathbf{R I}^{b}$} & \multirow{2}{*}{ MI } & \multirow{2}{*}{ Compounds } & \multicolumn{6}{|c|}{ Relative content $($ mean $\pm \mathrm{SD}) / \%^{c}$} \\
\hline & & & & & FD & MJ & NH & RY & PH & SH \\
\hline 25 & $\mathrm{~A} 25$ & 1449 & MS,RI,AD & $\begin{array}{l}(1 \mathrm{E}, 4 \mathrm{E}, 8 \mathrm{E})-2,6,6,9- \\
\text { tetramethylcycloundeca-1,4,8- } \\
\text { triene/ } \alpha \text {-caryophyllene }\end{array}$ & $1.2 \pm 0.04$ & nd & $2.27 \pm 0.05$ & nd & nd & nd \\
\hline 26 & A26 & 1464 & MS,RI,AD & $\begin{array}{l}(1 \mathrm{R}, 4 \mathrm{aR}, 8 \mathrm{aS})-7-\text { methyl-4- } \\
\text { methylidene-1-propan-2-yl- } \\
2,3,4 \mathrm{a}, 5,6,8 \mathrm{a}-\mathrm{h} \text {-xahydro-1H- } \\
\text { naphthalene/ } \gamma \text {-muurolene }\end{array}$ & $1.55 \pm 0.17$ & $6.30 \pm 1.85$ & $0.34 \pm 0.02$ & $0.12 \pm 0.05$ & nd & $0.04 \pm 0.01$ \\
\hline 27 & A27 & 1466 & MS,RI,AD & selina-4(14),7(11)-diene $/ \gamma$-selinene & nd & nd & $0.33 \pm 0.05$ & $0.09 \pm 0.03$ & $0.05 \pm 0.02$ & $0.04 \pm 0$ \\
\hline 28 & A28 & 1468 & MS,RI,AD & $\begin{array}{l}\text { (3R,4aS,8aR)-8a-methyl-5- } \\
\text { methylidene-3-prop-1-en-2-yl- } \\
1,2,3,4,4 \mathrm{a}, 6,7,8- \\
\text { octahydronaphthalene/ } \beta \text {-selinene }\end{array}$ & $0.23 \pm 0.02$ & $0.49 \pm 0.06$ & nd & nd & $0.17 \pm 0.06$ & nd \\
\hline 29 & A29 & 1472 & MS,RI,AD & $\begin{array}{l}\text { (3aS- (3aalpha,3bbeta, } \\
\text { 4beta,7alpha,7aS*))- 3a,3b,4,5,6,7- } \\
\text { hexahydro-3,7-dimethyl-4-(1-methyl } \\
\text { ethyl)-1H- } \\
\text { cyclopenta( } 1,3) \text { cyclopropa }(1,2) \\
\text { benzene/ } \alpha \text {-cubebene }\end{array}$ & $1.15 \pm 0.62$ & $2.63 \pm 1.1$ & nd & nd & nd & nd \\
\hline 30 & $\mathrm{~A} 30$ & 1480 & MS,RI,AD & $\begin{array}{l}\text { (1R,4aS,8aS)-7-methyl-4- } \\
\text { methylidene-1-propan-2-yl- } \\
\text { 2,3,4a,5,6,8a-hexahydro-1H- } \\
\text { naphthalene/ } \gamma \text {-cadinene }\end{array}$ & $1.46 \pm 0.11$ & $2.37 \pm 0.09$ & $0.38 \pm 0.03$ & nd & nd & nd \\
\hline 31 & A31 & 1481 & MS,RI,AD & $\begin{array}{l}\text { 2,2,4a,8-tetramethyl-1,2a, } 3,4,5,6- \\
\text { hexahydrocyclobuta[i]indene } / \alpha- \\
\text { panasinsen }\end{array}$ & $0.17 \pm 0$ & nd & $0.32 \pm 0.02$ & $0.09 \pm 0.01$ & nd & $0.05 \pm 0$ \\
\hline 32 & A32 & 1483 & MS,RI,AD & $\begin{array}{l}\text { 1,6-dimethyl-4-propan-2-yl-1,2,3,4- } \\
\text { tetrahydronaphthalene }\end{array}$ & nd & nd & $0.98 \pm 0.08$ & $0.16 \pm 0.05$ & $0.06 \pm 0.03$ & $0.09 \pm 0$ \\
\hline 33 & A33 & 1500 & MS,RI,AD & $\begin{array}{l}{\left[1 \mathrm{R}-\left(1 \mathrm{R}^{*}, 4 \mathrm{R}^{*}, 6 \mathrm{R}^{*}, 10 \mathrm{~S}^{*}\right)\right]-4,12,12-} \\
\text { trimethyl-9-methylene-5- } \\
\text { oxatricyclo[8.2.0.04,6]dodecane/ } \beta \text { - } \\
\text { caryophyllene oxide }\end{array}$ & $0.03 \pm 0.01$ & nd & nd & nd & nd & nd \\
\hline 34 & A34 & 1503 & MS,RI,AD & $\begin{array}{l}\text { 1,1,7-trimethyl-4-methylidene- } \\
2,3,4 \mathrm{a}, 5,6,7,7 \mathrm{a}, 7 \mathrm{~b} \text {-octahydro- } 1 \mathrm{aH}- \\
\text { cyclopropa[e]azulene/ } \\
\text { alloaromadendrene }\end{array}$ & $0.09 \pm 0$ & nd & $0.15 \pm 0$ & nd & nd & nd \\
\hline 35 & A35 & 1510 & MS,RI,AD & valencene & nd & $0.02 \pm 0.01$ & $1.35 \pm 0.05$ & $0.3 \pm 0.02$ & $0.27 \pm 0.09$ & $0.23 \pm 0.02$ \\
\hline 36 & A 36 & 1529 & MS,RI,AD & $\begin{array}{l}\text { 1,4-dimethyl-7-propan-2-ylidene- } \\
\text { 2,3,4,5,6,8-hexahydro-1H- } \\
\text { azulen/guaiene }\end{array}$ & nd & $0.02 \pm 0$ & nd & nd & nd & nd \\
\hline \multicolumn{11}{|c|}{ Aldehydes } \\
\hline 37 & B1 & 818 & MS,RI,AD & hexanal & $0.75 \pm 0.18$ & nd & $4.71 \pm 0.19$ & nd & $2.14 \pm 0.43$ & $1.57 \pm 0.25$ \\
\hline 38 & B2 & 1056 & MS,RI,AD & (E)-oct-2-enal & nd & nd & nd & nd & nd & $0.61 \pm 0.1$ \\
\hline 39 & B3 & 1105 & MS,RI,AD & nonanal & $0.59 \pm 0.18$ & $0.12 \pm 0.03$ & $1.2 \pm 0.3$ & $0.85 \pm 0.2$ & $0.34 \pm 0.01$ & $0.59 \pm 0.03$ \\
\hline 40 & B4 & 1210 & MS,RI,AD & decanal & $0.21 \pm 0.09$ & $0.09 \pm 0.02$ & $0.51 \pm 0.11$ & $0.56 \pm 0.42$ & $0.22 \pm 0.09$ & $0.6 \pm 0.04$ \\
\hline 41 & B5 & 1224 & MS,RI,AD & $\begin{array}{l}\text { 2,6,6-trimethylcyclohexene-1- } \\
\text { carbaldehyde/ } \beta \text {-cyclocitral }\end{array}$ & $0.03 \pm 0.01$ & nd & nd & $0.08 \pm 0.01$ & $0.06 \pm 0.02$ & $0.14 \pm 0.04$ \\
\hline 42 & B6 & 1275 & MS,RI,AD & $\begin{array}{l}\text { (2E)-3,7-dimethylocta-2,6- } \\
\text { dienal/citral }\end{array}$ & nd & nd & nd & nd & nd & $0.29 \pm 0.02$ \\
\hline \multicolumn{11}{|c|}{ Alcohols } \\
\hline 43 & $\mathrm{C} 1$ & 861 & MS,RI,AD & (E)-hex-3-en-1-ol & nd & $0.48 \pm 0.05$ & nd & $6.9 \pm 3.25$ & $13.43 \pm 2.07$ & $5.66 \pm 0.75$ \\
\hline 44 & $\mathrm{C} 2$ & 871 & MS,RI,AD & hexan-1-ol & $5.02 \pm 1.44$ & $1.81 \pm 0.01$ & $12.47 \pm 1.0$ & $27.05 \pm 2.61$ & $27.21 \pm 5.53$ & $15.69 \pm 2$ \\
\hline 45 & $\mathrm{C} 3$ & 965 & MS,RI,AD & heptan-1-ol & nd & nd & nd & $2.44 \pm 0.15$ & $1.77 \pm 0.2$ & $2.11 \pm 0.19$ \\
\hline 46 & $\mathrm{C} 4$ & 1069 & MS,RI,AD & octan-1-ol & nd & nd & nd & $1.74 \pm 0.32$ & $0.99 \pm 0.12$ & $1.67 \pm 0.1$ \\
\hline 47 & $\mathrm{C} 5$ & 1175 & MS,RI,AD & nonan-1-ol & nd & nd & nd & $0.55 \pm 0.12$ & $0.34 \pm 0.01$ & $0.72 \pm 0.02$ \\
\hline 48 & C6 & 1193 & MS,RI,AD & $\begin{array}{l}\text { 2-(4-methylcyclohex-3-en-1- } \\
\text { yl)propan-2-ol/ } \alpha \text {-terpineol }\end{array}$ & $0.01 \pm 0$ & nd & nd & nd & nd & nd \\
\hline 49 & $\mathrm{C} 7$ & 1515 & MS,RI,AD & $\begin{array}{l}(1 \mathrm{~S}, 4 \mathrm{~S}, 4 \mathrm{aR}, 8 \mathrm{aS})-1,6 \text {-dimethyl-4- } \\
\text { propan-2-yl-3,4,4a,7,8,8a-hexahydro- } \\
\text { 2H-naphthalen-1-ol/a-cadinol }\end{array}$ & $0.07 \pm 0.01$ & $0.38 \pm 0.1$ & nd & nd & nd & nd \\
\hline \multicolumn{11}{|c|}{ Ketones } \\
\hline 50 & D1 & 983 & MS,RI,AD & $\begin{array}{l}\text { 6-methylhept-5-en-2-one/methyl } \\
\text { heptenone }\end{array}$ & $2.76 \pm 0.66$ & $0.85 \pm 0.02$ & $2.98 \pm 0.21$ & nd & $8.49 \pm 0.86$ & $13.06 \pm 1.35$ \\
\hline 51 & D2 & 1544 & MS,RI,AD & $\begin{array}{l}\text { 4,4a-dimethyl-6-prop-1-en-2-yl- } \\
\text { 3,4,5,6,7,8-hexahydronaphthalen-2- } \\
\text { one/nootkatone }\end{array}$ & $0.11 \pm 0.01$ & nd & nd & nd & nd & nd \\
\hline \multicolumn{11}{|c|}{ Benzenes } \\
\hline 52 & E1 & 1019 & MS,RI,AD & $\begin{array}{l}\text { 1-methyl-4-propan-2-ylbenzene/ } \\
\text { para-cymene }\end{array}$ & nd & nd & nd & nd & $0.08 \pm 0.01$ & nd \\
\hline
\end{tabular}

${ }^{a}$ The code of aroma constitutes. ${ }^{\mathrm{b}}$ Identification method: MS, mass spectrum comparison using NIST and Wiley libraries; RI: retention index in agreement with literature value; AD: aroma description (odor). ${ }^{\mathrm{c}} \mathrm{SD}$ : standard deviation. ${ }^{\mathrm{d}}$ nd: not detected. 


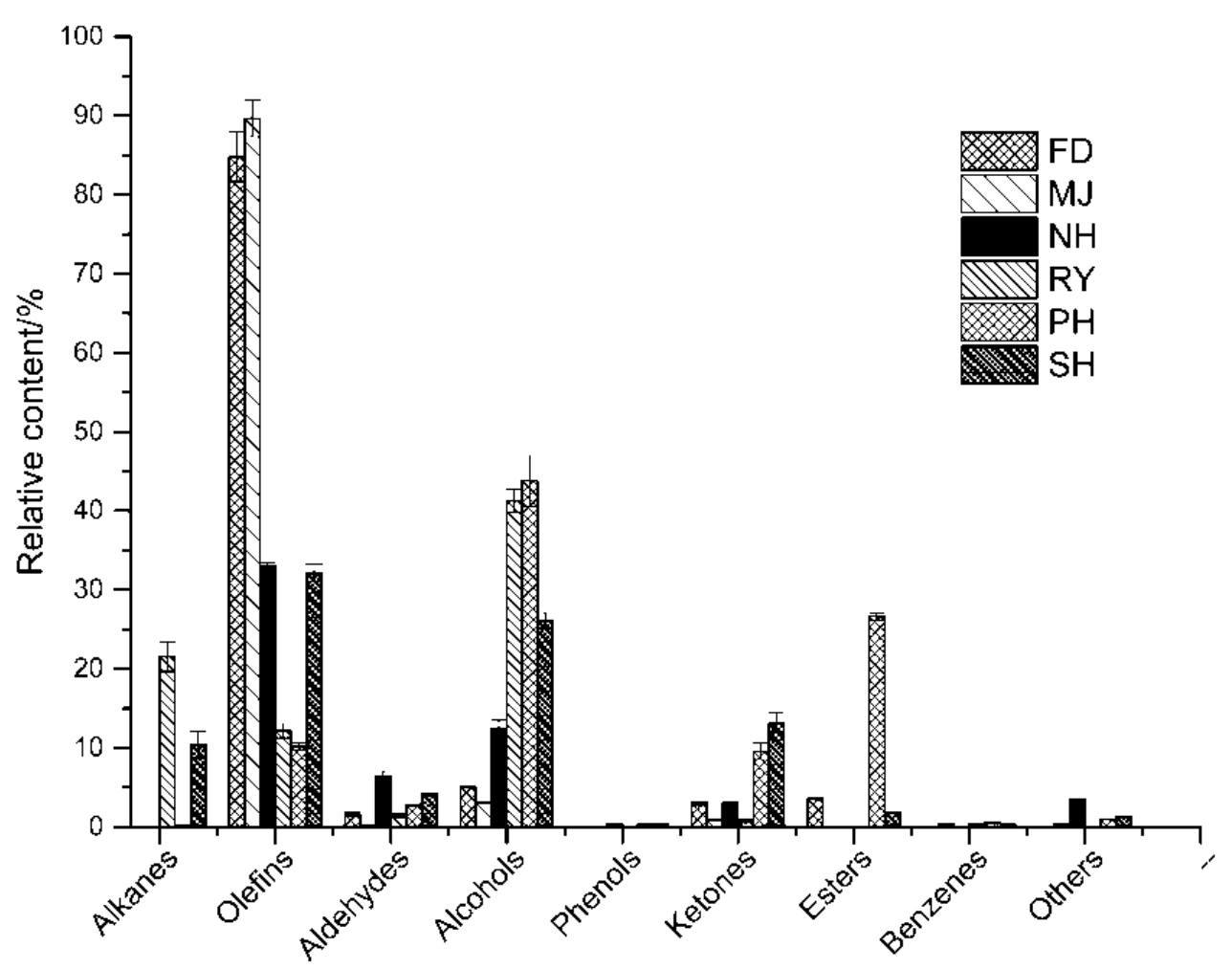

Figure 1. The composition and relative content (\%) of volatile compounds identified by SPME/GC-MS in different pink pomelo juices from China

According to the relative content of alkane classes, the RY samples $(21.55 \%)$ contained the highest amount, followed by $\mathrm{SH}$ samples $(10.4 \%)$. And a relative content of less than $1 \%$ was detected in other four samples.

The olefins, as the predominant family of volatile compounds in pink pomelo juices, owned the most kinds and highest content of volatiles when compared with other classes. The highest abundant samples were MJ samples $(89.65 \%)$, followed by FD samples $(84.79 \%)$, NH samples (33.05\%), SH samples (32.17\%), RY samples (11.92\%), PH samples (10.17\%). The most abundant compound was D-limonene (A6) occupying more than $30 \%$ of volatiles in FD samples. As one of the most important volatile in citrus juices, D-limonene was also identified to owning an comparative high content in the cultivar of pink and white pomelo juices from Malaysian [2], and the highest concentration for odor intensity of pummelo fruit from China [27]. The second highest content of this class was $\beta$-caryophyllene (A21) in SH samples (16.47\%), followed by $\delta$-cadinene (A24) $(9.58 \%)$ and germacrene D (A16) $(8.33 \%)$ in $\mathrm{MJ}$ samples, which was also reported by Cheong et al [2].

As reported, aldehydes play an important role in contributing to citrus flavour [28]. For aldehydes, the content was generally from $0.21 \%$ (MJ samples) to $6.42 \%$ (NH samples) among these six pink pomelo samples. Hexanal (B1) (4.71\%) was detected to be the most abundant one of this family in NH samples. Nonanal (B3) and decanal (B4) were also detected in all the samples, which showed a comparatively higher amount in this class.

Alcohols are another important volatile components in many fruits, including pomelos [25]. The most abundant alcohols were found in PH samples $(43.82 \%)$, followed by RY samples (41.26\%), SH samples (26.13\%), NH samples (12.47\%), FD samples (5.05\%), and MJ samples (3.11\%). Hexan-1-ol (C2) was the most important one among this class, occupying a large proportion and presenting in all the samples in, which was also identified in the orange cultivars of "Navelina" and "Salustiana" from Spain [29].

The phenols were only detected in the cultivars of $\mathrm{NH}$, $\mathrm{PH}$ and $\mathrm{SH}$, of which the relative content is from $0.29 \%$ to $0.43 \%$.

For ketones, the third largest class of volatile compounds, it is obvious that $\mathrm{SH}$ samples (13.16\%) and $\mathrm{PH}$ samples $(9.56 \%)$ has given a comparative higher content level, followed by $\mathrm{NH}$ samples (2.98\%), FD samples (2.97\%), MJ samples (0.87\%), RY samples $(0.76 \%)$. Methyl heptenone (D1) should be mentioned to owning the highest amounts in this class.

As another important aroma components in fruits, especially in citrus, esters, was observed to owning the highest relative content in $\mathrm{PH}$ samples (26.67\%). FD samples $(3.57 \%)$ showed a higher relative content than the SH samples $(1.9 \%)$ and NH samples $(0.07 \%)$. The family of benzenes and others, both occupied a small percentage (much less than $4 \%$ in all the samples) in all the classes of volatile compounds, which also should be mentioned.

\subsection{Analysis of Aroma-active Substances by GC-MS-O}

As we all known, the volatile compositions identified by GC-MS did not give us their roles in odor contribution which was affected by their threshold [27]. Accordingly, we detected the aroma-active components of different pink pomelo samples using GC-O. Among all the volatiles, a total of 38 volatile components were identified to be aroma-active constitutes by the frequency analysis method (DFA) method and given in Table 4 (detection frequency $\geq 2$ ). Four components, D-limonene (A6), nonanal (B3), decanal (B4), hexan-1-ol (C2) contributing more active to the odor of all pink pomelo juices, were determined by all 
assessors. D-limonene (A6) played an important role in the citrus sensory, which was also reported by other researchers [30]. The aroma-active substances identified in pink pomelo juice samples using DFA covers a wide range of functional and flavored components. The odor of these aroma-active compounds could be divided into seven classes and characterized as balsamic, turpentine, citrus, wood, herb, green and mint. These odor were all reported in previous study [28].

Table 4. Principal aroma-active compounds of different pink pomelo juices from China

\begin{tabular}{|c|c|c|c|c|c|c|c|c|}
\hline \multirow{2}{*}{ No. } & \multirow{2}{*}{$\operatorname{Codes}^{\mathrm{a}}$} & \multirow{2}{*}{ Odor $^{\mathrm{b}}$} & \multicolumn{6}{|c|}{$\mathrm{DF}^{\mathrm{c}}$} \\
\hline & & & FD & MJ & $\mathrm{NH}$ & RY & $\mathrm{PH}$ & $\mathrm{SH}$ \\
\hline 1 & A1 & balsamic, gasoline & 7 & 7 & 8 & 8 & & \\
\hline 2 & A2 & pine, turpentine & 5 & & & & & \\
\hline 3 & A3 & pine, resin, turpentine & 6 & & & & & \\
\hline 4 & A4 & balsamic, must, spice & 5 & & 7 & & & 6 \\
\hline 5 & A6 & citrus, mint & 8 & 7 & 8 & 8 & 8 & 8 \\
\hline 6 & A9 & lemon, resin & 6 & & & & & \\
\hline 7 & A10 & gasoline, turpentine & 8 & & & & & \\
\hline 8 & A11 & pine & 7 & & & 6 & & \\
\hline 9 & A13 & lemon & & 8 & 7 & & 8 & \\
\hline 10 & A14 & wood & 6 & 5 & 2 & & & 2 \\
\hline 11 & A15 & wood, spice & 3 & 5 & & & & \\
\hline 12 & A16 & wood, spice & 2 & 6 & 3 & 3 & & 4 \\
\hline 13 & A17 & herb, wax, fresh & 6 & & & & & \\
\hline 14 & A18 & wood, balsamic & 4 & 2 & & & & \\
\hline 15 & A19 & wood & 3 & 5 & & & & \\
\hline 16 & A 21 & wood, spice & & & 6 & 7 & 7 & 8 \\
\hline 17 & A22 & citrus, fruit & 7 & 8 & 6 & 7 & & 6 \\
\hline 18 & A23 & wood, earth, spice & & 6 & & & & \\
\hline 19 & A24 & thyme, medicine, wood & 4 & 7 & 2 & & & \\
\hline 20 & A25 & wood & 3 & & 4 & & & \\
\hline 21 & A26 & herb, wood, spice & 3 & 7 & 2 & 2 & & 2 \\
\hline 22 & A27 & wood & & & 3 & 2 & & \\
\hline 23 & A29 & herb, wax & 5 & 6 & & & & \\
\hline 24 & $\mathrm{~A} 30$ & wood & 4 & 7 & 4 & & & \\
\hline 25 & A32 & herb, spice & & & 3 & 2 & 2 & 2 \\
\hline 26 & A33 & herb, sweet, spice & 7 & & & & & \\
\hline 27 & A34 & wood & 2 & & 4 & & & \\
\hline 28 & A35 & green, oil & & 2 & 7 & 3 & 4 & 3 \\
\hline 29 & B1 & grass & 5 & & 7 & & 6 & 6 \\
\hline 30 & B3 & fat, citrus, green & 7 & 6 & 7 & 6 & 6 & 7 \\
\hline 31 & B4 & soap, orange peel, tallow & 6 & 6 & 7 & 8 & 7 & 8 \\
\hline 32 & B5 & $\operatorname{mint}$ & 5 & & & 5 & 7 & 6 \\
\hline 33 & B6 & lemon & & & & & & 8 \\
\hline 34 & $\mathrm{C} 2$ & resin, flower, green & 8 & 8 & 8 & 8 & 8 & 8 \\
\hline 35 & C5 & fat, green & & & & 7 & 6 & 7 \\
\hline 36 & C6 & mint & 7 & & & & & \\
\hline 37 & D1 & pepper, mushroom, rubber & 3 & 2 & 3 & & 5 & 6 \\
\hline 38 & D2 & grapefruit & 7 & & & & & \\
\hline
\end{tabular}

${ }^{a}$ Codes correspond to those in Table 1. ${ }^{\mathrm{b}}$ Odor description obtained from http://www.flavournet.org. ${ }^{\mathrm{c}}$ Sum of times determined by the panel of assessors.
As given in Table 4, the balsamic odor was probably due to styrene (A1) and $\beta$-myrcene (A4) in FD, MJ, NH and RY samples. The odor of turpentine may be caused by $\alpha$-pinene (A2), $\beta$-pinene (A3), $\gamma$-terpinene (A10), terpinolene (A11) and methyl heptenone (D1). The citrus odor may be due to the presence of D-limonene (A6), 3carene (A9), $\alpha$-terpinene (A13), $\beta$-cubebene (A22), nonanal (B3), decanal (B4), citral (B6), nootkatone (D2). The wood odor was possibly contributed by $\delta$-elemene (A14), $\beta$-caryophyllene (A21), $\delta$-cadinene (A24), $\gamma$ muurolene (A26). Elemene (A17), $\alpha$-cubebene (A29) and $\beta$-caryophyllene oxide (A33) probably contributed most to the herb odor in FD samples. And the green odor may be caused by hexan-1-ol (C2) in all the pink pomelo juices. The mint odor may be due to the presence of $\beta$ cyclocitral (B5) and $\alpha$-terpineol (C6) in the cultivar of FD, $\mathrm{RY}, \mathrm{PH}$ and $\mathrm{SH}$.
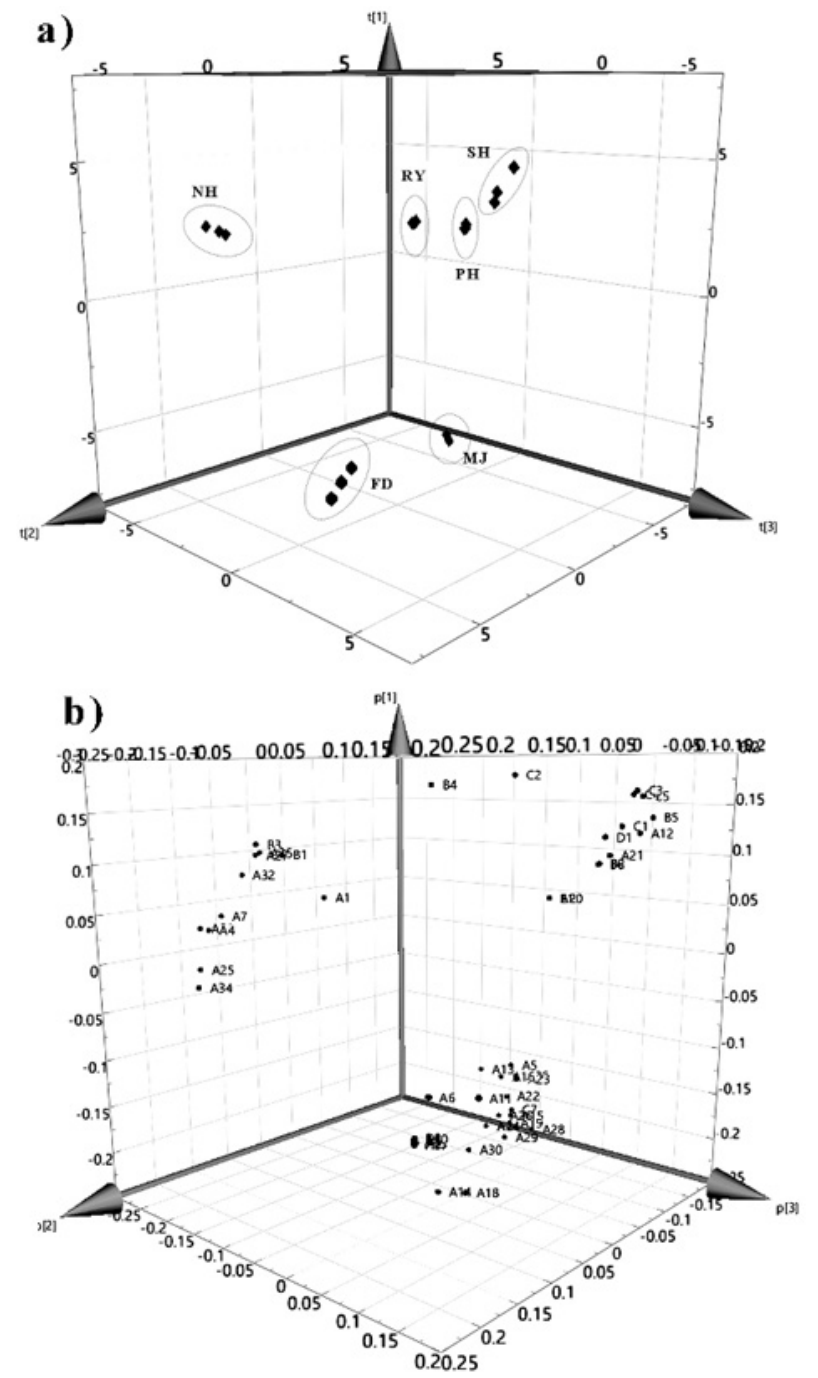

Figure 2. PC1 vs. PC2 vs. PC3 scatter plot of the main sources of variability among different pink pomelo juices (a) distinction between the cultivars (scores), $\mathrm{FD}, \mathrm{MJ}, \mathrm{NH}, \mathrm{RY}, \mathrm{PH}, \mathrm{SH}$; (b) relationships between the volatile compounds (loadings). Codes correspond to the compounds described in Table 2

\subsection{Principal Component Analysis of GC-MS Data}

As one basic method, multivariate analysis plays an important part in the sensory evaluation. In a large data set, 
PCA can decrease the number of dimensions and define the number of principal components on the basis of preserving the original information [31]. To distinguish different varieties, PCA was used to visualize the degree of contribution of volatiles components to all cultivators.

As shown in Figure 2a, the pink pomelo juices were successfully divided into six groups (FD, MJ, NH, RY, $\mathrm{PH}, \mathrm{SH}$ ) in a three-dimensional (3D) space on the basis of relationships between the varieties (scores plot) and their volatile relative contents (loading plot). The scores scatter plot for three principal components (PC1, PC2 and PC3) has given us the difference among these pink pomelo juice samples. Figure $2 b$, the corresponding loading plot, has showed the relative importance of each volatile component and the relations between volatile constitutes and samples. As we all know, the PC data could be used to replace the original data when an $85 \%$ cumulated reliability of the original dataset was achieved. Three principal components (PCs) were obtained from the pink pomelo juice data sets, accounting for $96.7 \%$ of the cumulative percentage of total variations, whereby PC 1, PC 2 and PC 3 accounted for $37.3 \%, 25.9 \%$ and $19.7 \%$ of the variance, respectively.

As clearly shown in Figure 2, the FD samples (FD1, FD1 and FD3) lied on the negative region of $\mathrm{PC} 1$ and positive region of $\mathrm{PC} 2$ and $\mathrm{PC} 3$, which was distinctly isolated from other cultivators. The MJ samples (MJ1, $\mathrm{MJ} 2$ and MJ3) located on the negative region of PC1, PC2 and PC3. The NH samples (NH1, NH1 and NH3) located on the positive region on $\mathrm{PC} 1$ and $\mathrm{PC} 2$, and negative region on PC3. The RY samples (RY1, RY1 and RY3), $\mathrm{PH}$ samples (PH1, $\mathrm{PH} 2$ and $\mathrm{PH} 3$ ) and $\mathrm{SH}$ samples ( $\mathrm{SH} 1$, $\mathrm{SH} 2$ and $\mathrm{SH} 3$ ) all lied on the positive region of $\mathrm{PC} 1$ and
PC3, and negative region of PC2, which were grouped with each other.

\subsection{Partial Least Squares-discriminant Analysis (PLS-DA) of Aroma-active Components}

As a successful classification technique [32], PLS-DA were applied to build linear discriminant models according to their volatile compositions attributes. Compared with PCA and other multiple regression, PLS-DA has advantages in combining and generalising features [33]. The PLS-DA model precisely classified the violatile components of an external validation subset with prediction ability of $100 \%$.

As showed in Figure 3, the location of 38 aroma-active components as dependent variables and seven sensory attributes as explanatory variables has given a good linear correlated model. Notably, the odor of citrus was situated around D-limonene (A6), $\alpha$-terpinene (A13), $\beta$-cubebene (A22), nonanal (B3), citral (B6) and nootkatone (D2); meanwhile the turpentine odor was mainly correlated with $\alpha$-pinene (A2), $\beta$-pinene (A3) and terpinolene (A11). The woody odor was located a bit far apart from other odors, surrounded by copaene (A15), germacrene D (A16), $\alpha$-gurjunene (A18), aromadendrene (A19) and $\beta$-caryophyllene (A21). Moreover, the odor of balsamic, turpentine, green, herb and mint were lied closely to each other. This PLS-DA model is good in correlating citrus odor, which is the dominant flavor of pink pomelo juices. Further more, the influence of aroma-active compounds of pink pomelo juice could be explored.

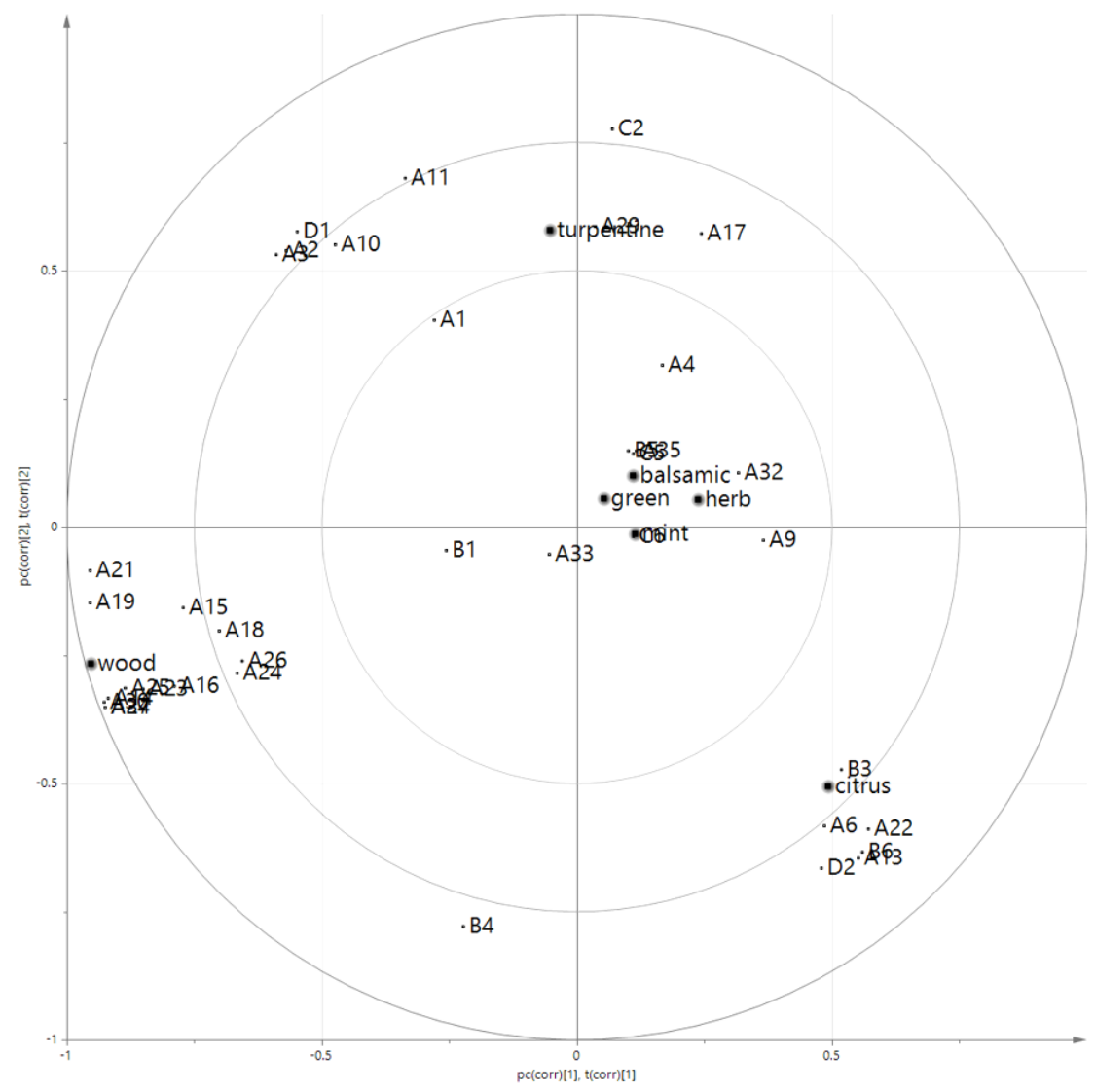

Figure 3. PLS-DA biplots of aroma-active compounds of pink pomelo juices correlating with seven different odors given as a two-dimensional representation of the scores 


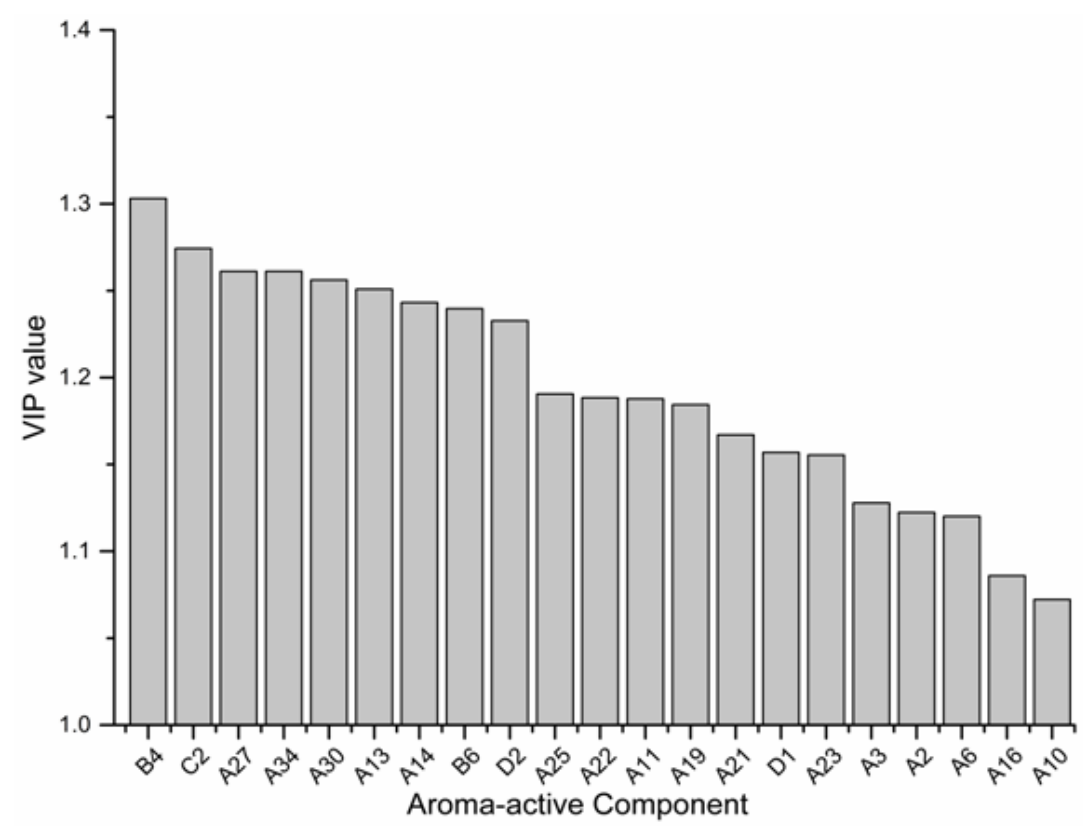

Figure 4. Aroma-active components of different pink pomelo juices, ordered by variable importance criterion VIP. Codes correspond to the compounds described in Table 2

Note that the VIP values given in the Figure 4 correspond to the model with selected variables. As a rule of thumb, it is customary to retain variables with VIP $>1$ [33], all the distinctive aroma-active component is considered as different varieties. Based on this rule, the distinctive aroma-active components that can distinguish the six grapefruit cultivars are decanal (B4), hexan-1-ol (C2), $\gamma$-selinene (A27), alloaromadendrene (A34), $\gamma$-cadinene (A30), $\alpha$-terpinene (A13), $\delta$-elemene (A14), citral (B6), nootkatone (D2), $\alpha$-caryophyllene (A25) and other 11 components. Hence, it is feasible to achieve the discrimination of pink pomelo varieties by multivariate statistical analysis.

\section{Conclusions}

As a pigmented variety, the volatile constituents of different pink pomelo cultivars, collected from different geographical origins of China were evaluated and characterized by combining the SPME/GC-MS-O, PCA and PLS-DA in this study. According to the PCA results, there were significant differences among different pink pomelo juices, and it was clear to distinguish these cultivars into different groups. In addition, we used the PLS-DA in the analysis of sensory perception, and distinguished the odors in pink pomelo juices caused by the aroma-active components. Hence, this study about the volatile profiles of China pink pomelo juices could be useful to establish a data base and form criteria for the quality control and identification of national pink pomelo juices. Moreover, this study may be useful to future work coupling sensory perception with regression analysis.

\section{Acknowledgements}

This work was supported by National Key R\&D Program of China (2017YFD0400705), National Natural Science Foundation of China (31401666) and Agricultural Scientific Research Outstanding Talent Training Project.

\section{References}

[1] Sawamura, M.; Shichiri, K.; Ootani, Y.; Zheng, X. H., STUDIES ON THE ESSENTIAL OILS OF POMELO .4. VOLATILE CONSTITUENTS OF SEVERAL VARIETIES OF POMELOS AND CHARACTERISTICS AMONG CITRUS SPECIES. Agricultural and Biological Chemistry 1991, 55, 2571-2578.

[2] Cheong, M. W.; Liu, S.; Zhou, W.; Curran, P.; Yu, B., Chemical composition and sensory profile of pomelo (Citrus grandis (L.) Osbeck) juice. Food Chemistry 2012, 135, 2505-2513.

[3] Azevedo, M. S.; Tischer Seraglio, S. K.; Rocha, G.; Balderas, C. B.; Piovezan, M.; Gonzaga, L. V.; Falkenberg, D. d. B.; Fett, R.; Leal de Oliveira, M. A.; Oliveira Costa, A. C., Free amino acid determination by GC-MS combined with a chemometric approach for geographical classification of bracatinga honeydew honey (Mimosa scabrella Bentham). Food Control 2017, 78, 383-392.

[4] Ramirezrodrigues, M. M.; Plaza, M. L.; Azeredo, A.; Balaban, M. O.; Marshall, M. R., Physicochemical and Phytochemical Properties of Cold and Hot Water Extraction from Hibiscus sabdariffa. Journal of Food Science 2011, 76.

[5] Vinaixa, M.; Schymanski, E. L.; Neumann, S.; Navarro, M.; Salek, R. M.; Yanes, O., Mass spectral databases for LC/MS- and GC/MS-based metabolomics: State of the field and future prospects. Trends in Analytical Chemistry 2016, 78, 23-35.

[6] Klockmann, S.; Reiner, E.; Cain, N.; Fischer, M., Food Targeting: Geographical Origin Determination of Hazelnuts (Corylus avellana) by LC-QqQ-MS/MS-Based Targeted Metabolomics Application. Journal of Agricultural and Food Chemistry 2017, 65, 1456-1465.

[7] Li, M.; Dai, G.; Chang, T.; Shi, C.; Wei, D.; Du, C.; Cui, H.-L., Accurate Determination of Geographical Origin of Tea Based on Terahertz Spectroscopy. Applied Sciences-Basel 2017, 7.

[8] Zhang, X.; Liu, Y.; Li, Y.; Zhao, X., Identification of the geographical origins of sea cucumber (Apostichopus japonicus) in northern China by using stable isotope ratios and fatty acid profiles. Food Chemistry 2017, 218, 269-276.

[9] Raymond, C. A.; Davies, N. W.; Larkman, T., GC-MS method validation and levels of methyl eugenol in a diverse range of tea tree (Melaleuca alternifolia) oils. Analytical and Bioanalytical Chemistry 2017, 409, 1779-1787.

[10] Hemalatha, R.; Nivetha, P.; Mohanapriya, C.; Sharmila, G.; Muthukumaran, C.; Gopinath, M., Phytochemical composition, GC-MS analysis, in vitro antioxidant and antibacterial potential of clove flower bud (Eugenia caryophyllus) methanolic extract. Journal of Food Science and Technology-mysore 2016, 53, 1189-1198.

[11] Qin, G.; Tao, S.; Cao, Y.; Wu, J.; Zhang, H.; Huang, W.; Zhang, S., Evaluation of the volatile profile of 33 Pyrus ussuriensis cultivars by HS-SPME with GC-MS. Food Chemistry 2012, 134, 2367-2382. 
[12] Xiao, L.; Lee, J.; Zhang, G.; Ebeler, S. E.; Wickramasinghe, N.; Seiber, J. N.; Mitchell, A. E., HS-SPME GC/MS characterization of volatiles in raw and dry-roasted almonds (Prunus dulcis). Food Chemistry 2014, 151, 31-39.

[13] Wang, Y.; Yang, C.; Li, S.; Yang, L.; Wang, Y.; Zhao, J.; Jiang, Q., Volatile characteristics of 50 peaches and nectarines evaluated by HP-SPME with GC-MS. Food Chemistry 2009, 116, 356-364.

[14] Riuaumatell, M.; Miro, P.; Serracayuela, A.; Buxaderas, S.; Lopeztamames, E., Assessment of the aroma profiles of low-alcohol beers using HS-SPME-GC-MS. Food Research International 2014, 57, 196-202.

[15] Shin, E.; Craft, B. D.; Pegg, R. B.; Phillips, R. D.; Eitenmiller, R. R., Chemometric approach to fatty acid profiles in Runner-type peanut cultivars by principal component analysis (PCA). Food Chemistry 2010, 119, 1262-1270.

[16] Shamsipur, M.; Yazdanfar, N.; Ghambarian, M., Combination of solid-phase extraction with dispersive liquid-liquid microextraction followed by GC-MS for determination of pesticide residues from water, milk, honey and fruit juice. Food Chemistry 2016, 204, 289-297.

[17] Tufariello, M.; Capone, S.; Siciliano, P., Volatile components of Negroamaro red wines produced in Apulian Salento area. Food Chemistry 2012, 132, 2155-2164.

[18] Singleton, V. L.; Orthofer, R.; Lamuelaraventos, R. M., Analysis of Total Phenols and Other Oxidation Substrates and Antioxidants by Means of Folin-Ciocalteu Reagent. Methods in Enzymology 1999, 299, 152-178.

[19] Cao, X.; Bi, X.; Huang, W.; Wu, J.; Hu, X.; Liao, X., Changes of quality of high hydrostatic pressure processed cloudy and clear strawberry juices during storage. Innovative Food Science and Emerging Technologies 2012, 16, 181-190.

[20] Luo, D.; Chen, J.; Gao, L.; Liu, Y.; Wu, J., Geographical origin identification and quality control of Chinese chrysanthemum flower teas using gas chromatography-mass spectrometry and olfactometry and electronic nose combined with principal component analysis. International Journal of Food Science and Technology 2017, 52, 714-723.

[21] Pang, X.; Chen, D.; Hu, X.; Zhang, Y.; Wu, J., Verification of Aroma Profiles of Jiashi Muskmelon Juice Characterized by Odor Activity Value and Gas Chromatography-Olfactometry/Detection Frequency Analysis: Aroma Reconstitution Experiments and Omission Tests. Journal of Agricultural and Food Chemistry 2012, $60,10426-10432$.
[22] Rouseff, R. L.; Perezcacho, P. R.; Jabalpurwala, F., Historical review of citrus flavor research during the past 100 years. Journal of Agricultural and Food Chemistry 2009, 57, 8115-8124.

[23] Gao, G.; Zhao, L.; Ma, Y.; Wang, Y.; Sun, Z.; Liao, X., Microorganisms and Some Quality of Red Grapefruit Juice Affected by High Pressure Processing and High Temperature Short Time. Food and Bioprocess Technology 2015, 8, 2096-2108.

[24] Yu, K.; Xu, Q.; Da, X.; Guo, F.; Ding, Y.; Deng, X., Transcriptome changes during fruit development and ripening of sweet orange (Citrus sinensis). Bmc Genomics 2012, 13.

[25] Zheng, H.; Zhang, Q.; Quan, J.; Zheng, Q.; Xi, W., Determination of sugars, organic acids, aroma components, and carotenoids in grapefruit pulps. Food Chemistry 2016, 205, 112-121.

[26] Perezcacho, P. R.; Rouseff, R. L., Fresh squeezed orange juice odor: a review. Critical Reviews in Food Science and Nutrition 2008, 48, 681-695.

[27] Ni, H.; Hong, P.; Ji, H. F.; Sun, H.; Chen, Y. H.; Xiao, A.; Chen, F., Comparative analyses of aromas of fresh, naringinase-treated and resin-absorbed juices of pummelo by GC-MS and sensory evaluation. Flavour and Fragrance Journal 2015, 30, 245-253.

[28] Perezcacho, P. R.; Rouseff, R. L., Processing and storage effects on orange juice aroma: a review. Journal of Agricultural and Food Chemistry 2008, 56, 9785-9796.

[29] Julian Cuevas, F.; Moreno-Rojas, M.; Jose Ruiz-Moreno, M., Assessing a traceability technique in fresh oranges (Citrus sinensis L. Osbeck) with an HS-SPME-GC-MS method. Towards a volatile characterisation of organic oranges. Food Chemistry 2017, 221, 1930-1938.

[30] Brattoli, M.; Cisternino, E.; Dambruoso, P. R.; De Gennaro, G.; Giungato, P.; Mazzone, A.; Palmisani, J.; Tutino, M., Gas Chromatography Analysis with Olfactometric Detection (GC-O) as a Useful Methodology for Chemical Characterization of Odorous Compounds. Sensors 2013, 13, 16759-16800.

[31] Rodriguezcampos, J.; Escalonabuendia, H. B.; Orozcoavila, I.; Lugocervantes, E.; Jaramilloflores, M. E., Dynamics of volatile and non-volatile compounds in cocoa (Theobroma cacao L.) during fermentation and drying processes using principal components analysis. Food Research International 2011, 44, 250-258.

[32] Nocairi, H.; Qannari, E. M.; Vigneau, E.; Bertrand, D., Discrimination on latent components with respect to patterns. Application to multicollinear data. Computational Statistics \& Data Analysis 2005, 48, 139-147.

[33] Hervé, Partial Least Square Regression PLS-Regression. 2007. 